\title{
STUDENT PROJECT: REVIEW AND VERIFICATION OF THE BIRCH COLLECTIONS AT THE NATIONAL BOTANIC GARDENS OF IRELAND
}

\author{
Susan Foreman ${ }^{1}$
}

\begin{abstract}
Without careful record-keeping and a rigorous verification process, living plant collections are of limited scientific value. Living collections need to be managed to ensure that plants are correctly identified, that full provenance information is collated and recorded, that current taxonomic or classification systems are used and, lastly, that nomenclature is accurate. To achieve this, a number of tasks need to be undertaken, including maintaining accurate records of a plant's provenance, collecting and preparing voucher specimens in a herbarium, reviewing the scientific literature and identifying and correctly naming the individual plant. Every plant in a collection essentially has three elements to its identity: first, its provenance (how it came into the collection, and from where); second, that the individual plant is correctly associated with the correct provenance information (there may be several accessions of the same taxon in a collection); and third, that it is correctly identified and named. The first element is supported by a (preferably electronic) record system; the second is evidenced through the use of an accession number and qualifier that identify the individual plant. The third element of identity is open to reinterpretation when, for example, a specimen reaches maturity and flowers for the first time, or through taxonomic or nomenclatural changes. The entire process involves a range of disciplines and techniques, from record-keeping, archiving, mapping, literature searching, taxonomy, labelling and herbarium techniques, and provides a student with the opportunity to experience the full compass of activities undertaken at a botanic garden.
\end{abstract}

\section{NATIONAL BOTANIC GARDENS, GLASNEVIN}

The National Botanic Gardens of Ireland were founded in Glasnevin, Dublin in 1795. Over this time many plants have been brought or given to the gardens, including birch seed from wild-collected species and specimens grown in other botanic gardens, nurseries and collections from around the world.

\section{METHODOLOGY}

This project set out to review the status of the living collection of Betula within the National Botanic Gardens of Ireland. For each accession a herbarium specimen was made and notes were taken of the tree's size and appearance. During spring and early summer of 2009, samples of leaves, bark and catkins were made where possible. The

1. Susan Foreman was a student of the BSc in Horticulture at the Institute of Technology Blanchardstown in conjunction with College of Amenity Horticulture, National Botanic Gardens, Glasnevin. She graduated in 2010 and is now a Horticultural Advisor at Kinsealy Garden Centre, Co. Dublin. Address: 13 Grange Park Rise, Raheny, Dublin 5. 
names, accession number and exact location in the garden were all noted. A number of other trees, some from natural regeneration, were also noted and recorded in the same manner. The findings were updated to the living plant catalogue, and herbarium species were allocated with qualifiers so that they now form an integral part of the living catalogue.

THE GENUS BETULA

\section{Taxonomy}

The family Betulaceae comprises six genera: Alnus, Betula, Carpinus, Corylus, Ostrya and Ostryopsis (Chen et al., 1999). Formerly the last four genera were placed in Corylaceae on account of their seeds comprising hard-shelled nuts. Alnus and Betula also have fruits which are technically nuts, but they are small, soft-walled and have minute papery wings. Betula is distinguished by having catkins which disintegrate at maturity unlike the infructescence of Alnus, which is woody and remains on the tree after the seeds have been shed. The name used to describe the fruit of Betula has been referred to as a nutlet or a samara, depending on the botanist. Further, other workers interpret the female infructescence as a compound fruit. For example, Spjut (1994) uses the term "achenoconum".

The number of species within the genus is much debated in the literature, with figures ranging from 30 to 120 (De Jong, 1992). The divergent views are a result of the variability shown in individuals. The problems with identifying Betula are compounded by the degree of hybridisation that can occur, as well as by the conflicting keys, and the paucity of clear diagnostic characters.

The genus can be divided into four sections based on geography, bark colour and species concept (Huxley, 1992; De Jong, 1992). Also sometimes used to distinguish between sections is whether the bark contains methyl salicylate (oil of wintergreen). Section Betula comprises the white-barked birches such as B. pendula or B. papyrifera, which are quick growing and short-lived, prefer high light levels and lack methyl salicylate. The section Costate or monarch birches includes species B. alleghaniensis and $B$. maximowicziana. These are longer-lived, dislike waterlogging and will tolerate shade; some species have methyl salicylate. The third section is Chamaebetula, the bog or dwarf birches, B. nana and B. humilis, which are from arctic or mountain regions (Huxley, 1992). There is no mention in the literature of whether this section has methyl salicylate in its bark. Some taxonomists recognise a fourth section, Acuminatae, which includes birches from China and the Himalayas (De Jong, 1992).

Characters used in identifying birches can be summarised as follows:

- size of tree and pendulous nature of branches

- bark colour, texture and degree of peeling

- twig: degree of pubescence, presence of resinous glands 
- leaf: size, shape, texture, margin, vein number, pubescence

- catkin: position (erect/pendulous), ratio of width to length

- bract shape

- nutlet: shape and size of wings

\section{Bark characteristics}

The bark of many birch species is usually recognisably white; this whiteness is caused by a wax called betulin (Ashburner, 1992). White bark is not universal, however, and some have red, pink, grey or buff bark. In many species the bark of older trees begins to peel to reveal white bark beneath. The young twigs tend to start off as brown to red in colour and depending on the species and growing conditions will turn white with age. Because of the variability of bark colour it is not possible to identify most birches by bark characters, but it provides a useful indicator.

Bark characteristics help to assign specimens to groups or sections (Ashburner, 1992). Bark texture can be helpful in identification: B. ermanii peels in platelets in older trees, while $B$. utilis has a velvet-like texture peeling in paper-thin strips. Some species, such as B. szechuanica, B. platyphylla or B. papyrifera, can have bark with an outer layer of chalk-like farina that will come off on the hand if rubbed. Fig. 1 shows the variety of colour and texture between species. Other Betula vary in their sizes and colour of lenticels.

Peeling cannot be used as a character for identification as most birch peel in some way. However, some species tend to crack while others curl. Betula pendula, for example, forms black fissures at its base with age but only in some populations where growth rate is fast enough for the bark not to peel off but to crack instead. This is another indicator in identification but not a definitive characteristic of any one species (Ashburner, 1992).

\section{Inflorescence}

Plants vary from small shrubby alpine species to trees $30 \mathrm{~m}$ tall. All species are monoecious. The staminate, or male, catkins are found at the ends of branches in clusters and are generally pendulous. They are cylindrical and generally longer than the female catkins. They form in autumn and can be seen, tightly closed, on the trees during winter, opening and expanding in spring. In general, each male catkin is constructed of many overlapping bracts. Each primary bract protects a cluster of three flowers each made up of three stamens with two half anthers. The numbers of flowers, stamens and anthers can vary with each section or sub-group (De Jong, 1992; Spongberg, 1990; Huxley, 1992; Clarke, 1996).

Female, or carpellate, catkins are apical and are usually shorter than the males. They may stay erect or become pendulous, dispersing their seed in autumn. Each catkin is composed of many bracts within each of which a female flower is held with two linear 
A

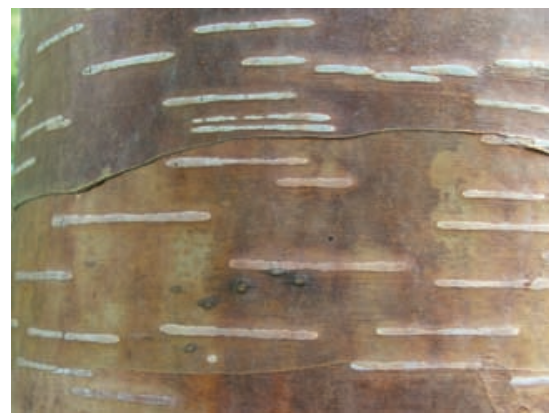

C

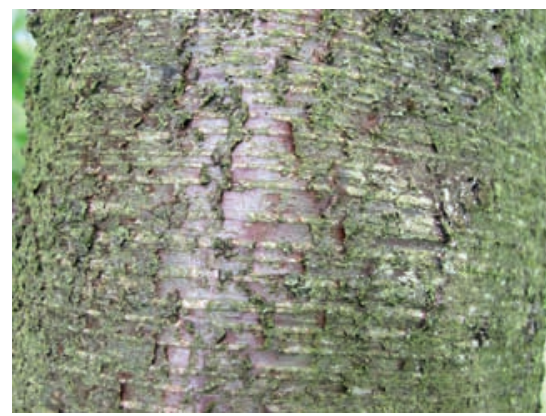

$\mathbf{E}$

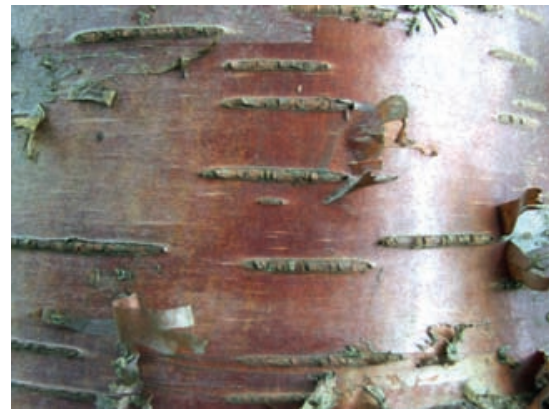

G

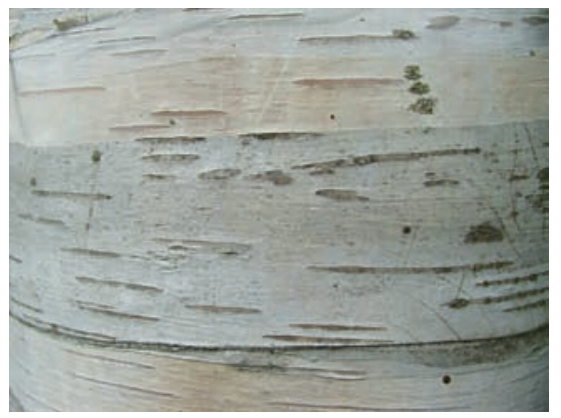

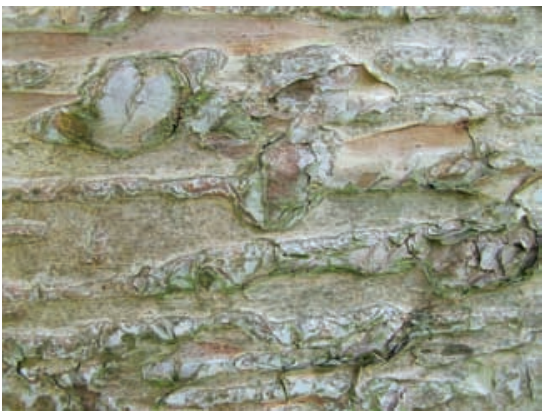

D

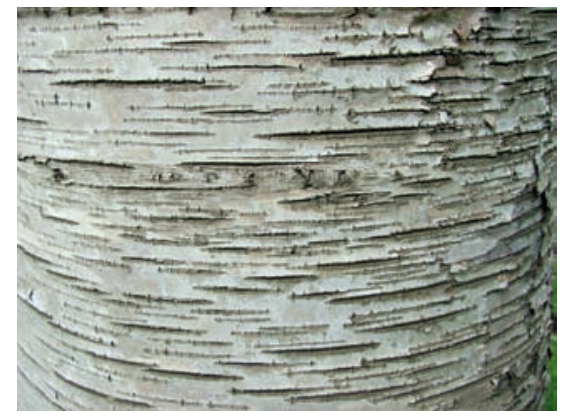

$\mathbf{F}$
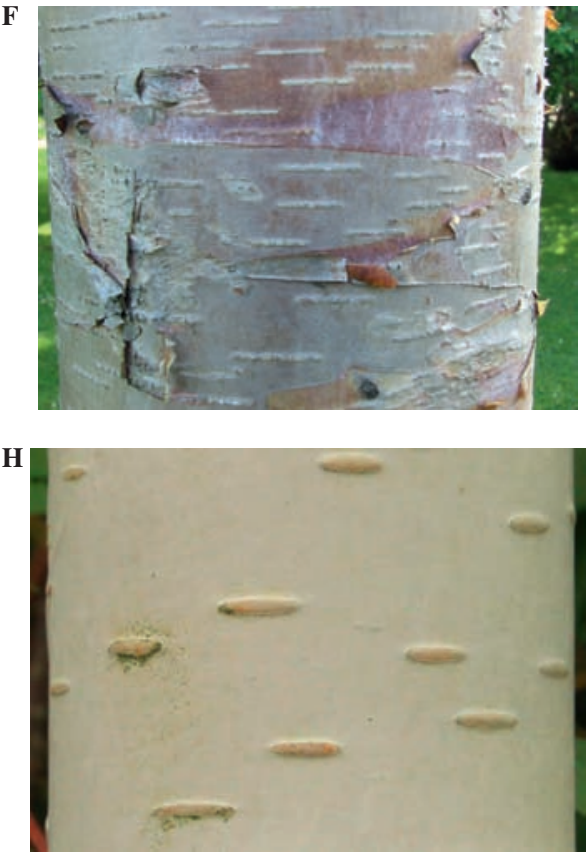

Fig. 1 Betula species and varieties showing the variation in colour and texture between species. Note that within species, for example $B$. utilis, colour also varies.

A) B. albosinensis B) B. ermanii C) B. lenta D) B. papyrifera E) B. pubescens F) B. utilis G) B. utilis $\mathrm{H}$ ) $B$. utilis var. jaquemontii. Photos: Susan Foreman. 
styles. These persist on the naked fruit, which comprises a single-seeded nutlet with membranous lateral wings of various sizes (De Jong, 1992; Spongberg, 1990; Huxley, 1992; Clarke, 1996).

\section{Infructescence}

The infructescence provides particularly useful characters. The relative sizes and angles of the three-lobed or trident-shaped bract and the size of the wings of the fruit are often diagnostic. The size and shape of the wings and nutlet can help in identification of species. The number of seeds per catkin can vary between 85 and 468 depending on species and growth rate (De Jong, 1992).

\section{DISTRIBUTION}

Many Betula tolerate inhospitable soils. They are found in temperate climates and colder regions of Europe, Japan, China, Himalaya and parts of Russia, the USA and Canada (Sargent, 1905).

In a paper on Betula presented at a Betula symposium hosted by the International Dendrology Society, de Jong (1992) stated that most botanic gardens and arboreta have "less than $50 \%$ of their birches correctly labelled".

In the past records held of plants at the National Botanic Gardens, Glasnevin have not been as informative as they could have been, and it was not until the 1970s that accession numbers were applied to the plants in order to improve record-keeping. Within the Betula collection 30 specimens have an accession number beginning with the letters XX, which means that the year of arrival and the provenance are presently unknown. A total of twenty-six trees had known provenance records, whilst ten specimens had no label at the time of the survey, some being spontaneous recruits in the collection and others being part of a woodland planting in the Native Beds and Flora of Ireland section.

\section{HERBARIUM SPECIMENS}

The Herbarium in the National Botanic Gardens, Glasnevin is an amalgamation of two historical collections. The first was the National Herbarium, which was formerly held at the National Museum in Kildare Street, Dublin until it was moved to Glasnevin in the summer of 1970. The second collection was the Garden Plant Herbarium and was held at the National Botanic Gardens; this comprises specimens from the living collections made in the early decades of the 20th century. A large collection of cultivated birches from private and public collections throughout Britain and Ireland was made by Augustine Henry (1857-1930) between 1900 and 1930. All herbarium specimens of Betula were used as a reference collection during the identification process for this project. 


\section{Specimen collection}

In order to collect useful herbarium specimens of lasting value, minimum standards needed to be adhered to. The Herbarium Handbook (Bridson, 1992) gives full and thorough instruction in best practice.

Specimens should be taken when dry, as damp samples slow down the process of drying and encourage the growth of mould. However, this was not always possible as collection times were limited and specimen details such as catkins could have been blown away while waiting for dry weather. Tools required for the task were sharp secateurs and an aerial pruner, plastic Ziploc ${ }^{\circledR}$ bags, herbarium cards, a pen, lists of plants to be collected and a map of the position of each plant. A thorough search of the gardens was made and a further ten plants, which were not previously mapped and were not on the database list, were found.

Details noted on the herbarium card included the accession identification number, the name on the tree label, the country of origin (as noted on the label), the common name (if present on the label), the date the sample was taken, the collector's name (in this case Susan Foreman), information noted about the specimen including its state of health, habit, bark colour and texture, height and trunk girth and its exact position in comparison with the map. Also noted were any other details which may have been of help in identifying the specimen and which would not be preserved in the collected material.

Specimens were taken with plenty of leaf and stem along with any buds and male or female catkins, which are all needed for identifying the plant; where possible bark samples were also taken. Where bark could not be peeled off without damage to the tree a photo was taken. Specimens were selected that had no disease or distortion through pest damage. The specimen and the herbarium card with all details noted were placed in the Ziploc ${ }^{\circledR}$ bag and returned to the Herbarium. Photographs were taken of each individual tree and its bark.

\section{Drying and pressing specimens}

Specimens were dried between dry sheets of newspaper where they were positioned roughly into the shape required for mounting with the leaves and the parts spread out. Finer adjustments were made in the first few days of drying when the samples were still supple. Once dry the specimen will break if moved or bent and leaves which have become folded during the process are not recoverable. One leaf was turned on each specimen to enable examination of the underside once mounted.

The label was tied onto each specimen during the whole drying process, ensuring that it could not be mixed up or separated from it. If the label is separated from the specimen, the sample has to be discarded. All small parts (such as seeds or bark) were placed in a small envelope with the number and name of the specimen and this was placed within the same section of newspaper. 
The collection was left to dry overnight in a cool place as this ensured that the specimen would keep some of its colour. If it had been dried out in heat, the sample would have gone brown. The following day, the newspaper was changed. The damp paper was placed back into the drying room to dry out for reuse. This process was continued over a three-week period until all the samples were dry and ready for decontamination.

\section{Decontaminating specimens}

Before mounting the dry specimens, the entire collection was placed into large plastic Ziploc $^{\circledR}$ bags and placed in a freezer. This is essential in order to kill any pests or their eggs. Some pests can cause devastation to a herbarium, such as Stegobium paniceum (herbarium beetle) and Lasioderma serricorne (tobacco beetle). There are two parts to this process: the chill time and the kill time.

The chill time is the time it takes for a specimen to reach $-18^{\circ} \mathrm{C}$ at its centre. The paper will cause some insulation effect so this time is calculated at approximately 17 hours. Very woody material takes longer. The kill time is the time required to kill pests at a constant $-18^{\circ} \mathrm{C}$; experiments have found that the longest kill time is nine hours for most pests. Specimens collected within Ireland are normally left in the freezer for 26 hours, which is thought to be sufficient to kill most, if not all, Irish pests. The specimens in this project were left in the freezer for 48 hours to comply thoroughly with best practice. The freezer used was a chest freezer preset to $-18^{\circ} \mathrm{C}$.

If it is thought that some pests have activated their hibernation sequence in order to live through the freezing then a double freeze can take place. In this process a 24-hour period is undertaken as above then the sample is brought back to room temperature and later frozen again. The pest cannot re-hibernate so dies. As yet none of the most destructive insects have been found in the Herbarium at the National Botanic Gardens, Glasnevin. The atmosphere of the Herbarium is dry, and this helps to control beetles as they require a higher humidity level to breed successfully.

Once removed from the freezer the specimens, still in their Ziploc ${ }^{\circledR}$ bags, were placed into the drying room for a further 24 hours in order to dry completely from the freezing process. Once defrosted they were individually mounted. It is important to keep the specimens in the plastic bags while they thaw out, to prevent condensation from any humidity in the air.

\section{Mounting specimens}

Each specimen was checked before mounting to ensure that it was totally dry. The paper used was archival quality acid-free mounting card. Fast-drying PVA glue was used to attach the specimen to the sheet. The glue was applied to the stalk and on the leaves. The specimen was then placed on the sheet and arranged to display all features as clearly as possible. Small lead weights were placed down on appropriate parts of the specimen in 
order to ensure that it adhered to the paper. The label was attached, as was the envelope with plant parts which were too small to attach by themselves. The whole sheet was left for several hours while the glue dried (see Fig. 2).

Once mounted, the Betula specimens were left in a carefully tied up bundle in the mounting room until the identification process could take place. The specimens were then frozen before being brought into the Herbarium for identification.

In December a further collection took place of the catkins which had not been obtained during the first collection period. These went through the same drying and freezing process as described above, before being mounted onto the original sheets with the new collection date noted.

Appendix 1 shows a copy of the pro-forma sheet filled in as part of the identification process.

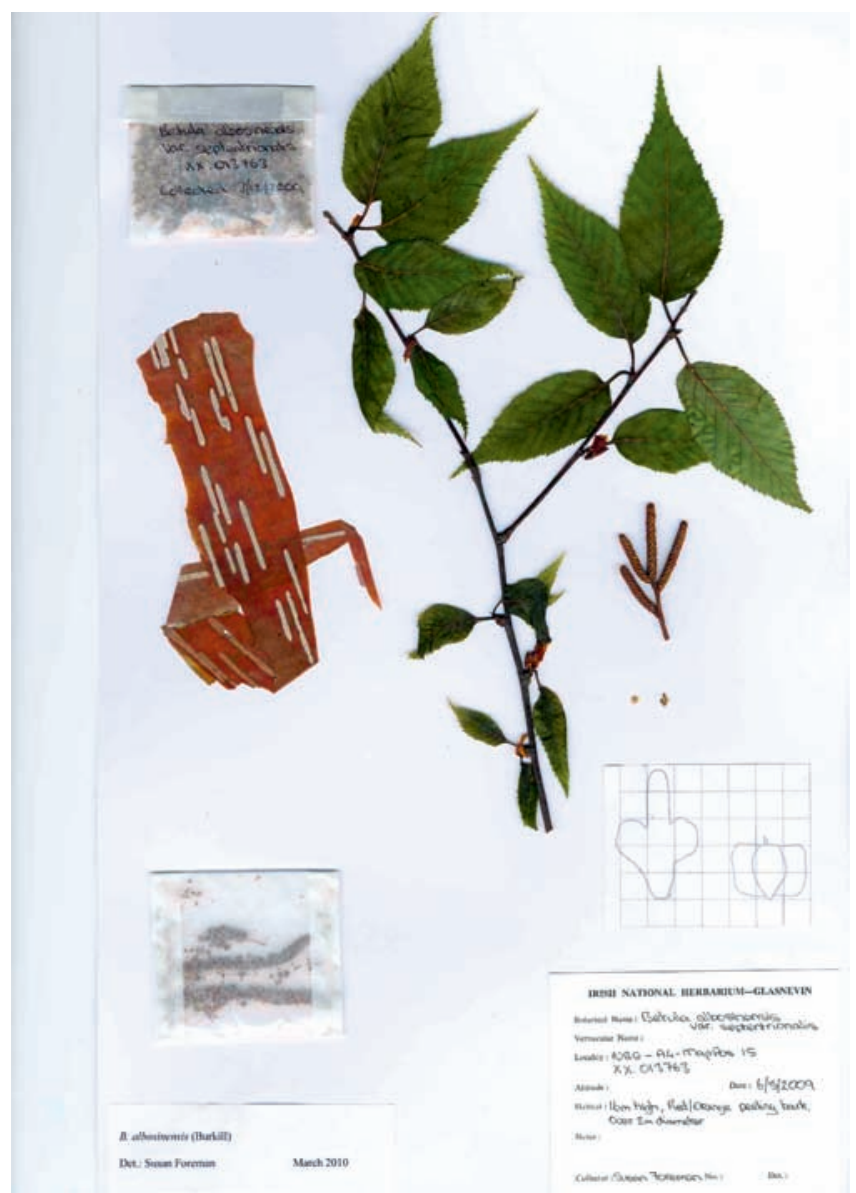

Fig. 2 Herbarium specimen of Betula albosinensis var. septrionalis. Photo: Susan Foreman. 


\section{THE IDENTIFICATION PROCESS}

The first stage of the identification process was to draw each seed and bract to scale. A good representative nutlet and bract from each specimen was selected and with the aid of graph paper they were scaled up $\times 10$ in size. These scaled drawings were attached to each herbarium specimen to provide information during the identification process. The relevant nutlet and bract were also glued onto the sheet, using PVA glue, for further reference in the future.

The specimens were sorted into the three main regions for Betula: North America, Europe and north-east Asia. A fourth category was made for all the specimens not determined to species. All the trees which had no label and were not listed in the database were temporarily given the title Betula sp.

\section{Reference material}

Many books were used in the identification of specimens covering the three main areas of the Betula range and all have been listed in the bibliography below. Betula are partially identified by their bracts and seeds, but not all books include drawings. Many books were referenced in order to obtain the correct drawings and pictures of these parts. Specimen nomenclature was checked against the World Checklist and Bibliography of Fagales (Govaerts \& Frodin, 1998) and name changes or errors to names were noted.

\section{Botanical keys}

Botanical keys were used to correctly identify the plants. As the family and genus were already known it was possible to proceed straight to relevant Betula keys covering the various geographic ranges.

\section{Identification procedure}

The process of using keys and comparing specimens against named material or descriptions requires skilled observation, interpretation and a certain amount of experience. For the initial identification, it was assumed that all specimens in the collection were accurately named. Each specimen was compared to a description of that species as well as to verified herbarium material if present. A pro-forma sheet was prepared that enabled each character to be compared against published descriptions. This enabled errors or oversights to be quickly spotted and provided an accurate reference. If the specimen did not match the description or named material it was redetermined using the published keys. After this process, if a different species was identified, it was again compared to a full species description and a new pro-forma sheet was filled in to ensure that the new determination was correct (see Appendix 1). 


\section{Taxonomic problems and terminology}

A large number of the previously unidentified Betula sp. specimens were determined as belonging to one of three species: B. pendula, B. pubescens or B. papyrifera. The identity of several specimens remained ambiguous, and these were assumed to be hybrids, the parentage of which was unidentifiable. Several Latin terms are used by taxonomists to account for these difficulties and are described as 'qualifications' in this project:

- $C f$ is an abbreviation for the Latin confer, meaning 'compare'. "This can be placed before the species name to imply that the specimen does not exactly match that species but should be compared with it." (Bridson \& Forman, 1992).

- Aff is an abbreviation for the Latin affinis, meaning 'related to'. "This can be placed before the species name to imply that the specimen does not exactly match that species but is related to it. It is a more definite expression of affinity than $c f$. ." (Bridson \& Forman, 1992).

- Indet. is an abbreviation for the Latin indeterminavit, meaning that "the specimen has not been, or cannot be, identified by the determinavit - the person who is verifying the specimen" (Bridson \& Forman, 1992).

\section{RESULTS AND CONCLUSIONS}

Seventy-one birch trees were found in the collections of the National Botanic Gardens, Glasnevin. These varied in age from saplings to mature trees over 100 years old. They also varied in health from those with good vitality to those which already had deadwood in almost half the canopy. All visible damage was noted on each specimen and on the database record. Of these 71 trees, herbarium specimens were made of 66. Suitable specimens could not be made of the remaining five.

Since the first collection date of 5 May 2009, seven of the Betula originally sampled had been removed from the grounds. Five of the deaths were assumed to be through infection by the fungal disease Phytophthora. One tree was blown down during bad weather in November 2009 and one was felled because of severe damage to the trunk causing death (McNally, pers. comm., March 2010).

Of the 66 specimens collected and mounted for identification catkins were collected for 11 during the first collection period. A further 33 specimens were gathered in December. Twenty-two specimens remained without catkins.

The provenance of all the trees was checked, using the handwritten ledgers as well as the electronic database. Of the 66 trees, the provenance could be confirmed for 27. The names and labels of 11 trees were verified as being correct. Five trees bore outdated names requiring an update to the nomenclature in the database records. A total of 16 trees were therefore correctly identified. Four trees that were previously named have now been assigned as having inconclusive identities, and the identities were qualified as $c f$. A total of 46 trees were incorrectly identified; of these 16 were assigned a confident 


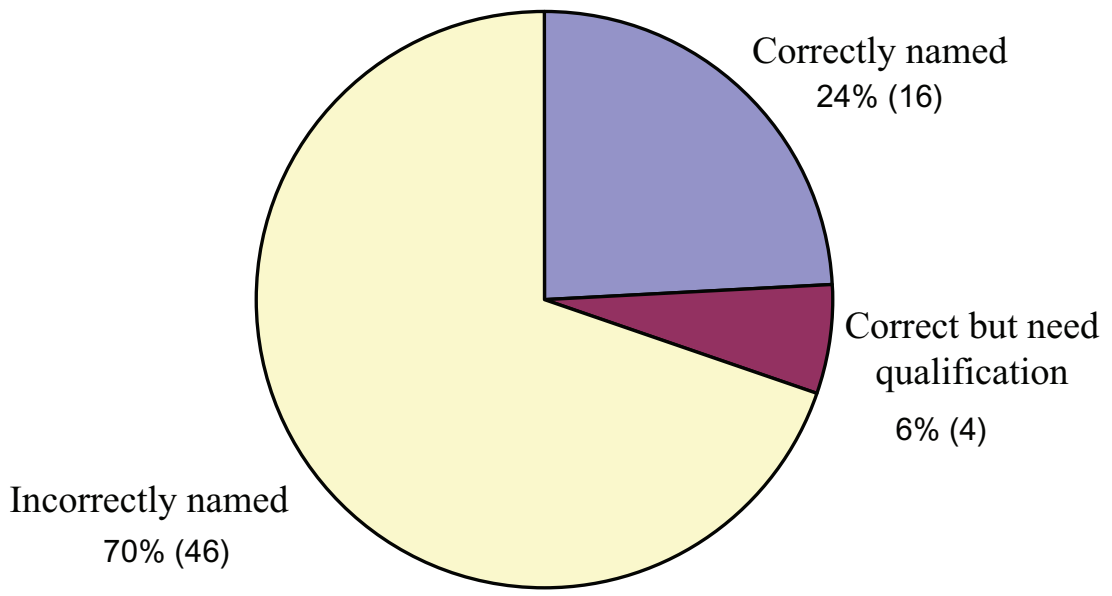

Fig. 3 Verification status of the 66 birch trees during the survey.

identity, a further 18 were given qualified names and 12 were unidentifiable - of these, 4 had previously been identified to genus level.

Twelve of the 66 trees could not be identified to species level. It is likely that they represent hybrid origin material - many of garden origin. It was felt that identifications could be achieved for four of these if more complete fertile material was available. Previous taxonomists had left the identity of several of these individuals as Betula sp. Thirty-three of the trees could be identified to species level as hybrids or cultivars with reasonable confidence. The remaining 21 trees could only be identified using the

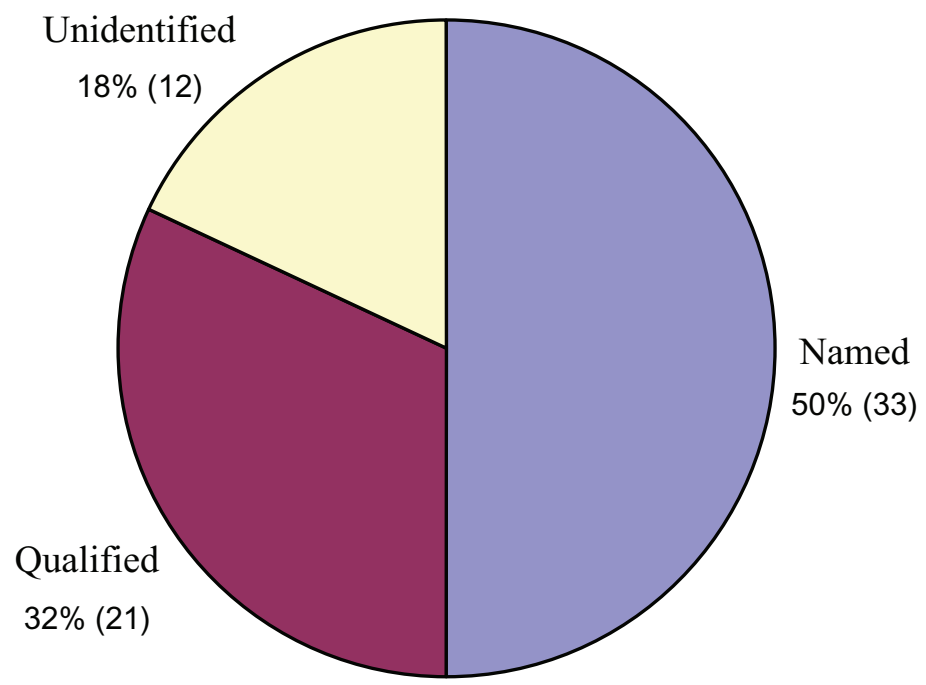

Fig. 4 Verification status of the 66 birch trees after the survey. 
qualifications described above to three taxa $B$. cf. papyrifera, $B$. cf. pendula and $B$. cf. pubescens.

The remaining eight may prove to be of hybrid origin, however since their provenance is also unknown, they have limited botanical merit and can be replaced with collections of known provenance.

De Jong (1992) stated that most botanic gardens and arboreta have "less than $50 \%$ of their birches correctly labelled". This project considerably improved the verification status of the collections at Glasnevin.

\section{RECOMMENDATIONS}

Of the 30 Betula species most widely recognised by experts, the National Botanic Gardens of Ireland at Glasnevin grow 11 species, with a possible further 4 subject to identification. In order that the Betula collection represents a good cross-section of the four sections of Betula and a selection of cultivars, a proposed list of the taxa that could be added to the current collection was drawn up. In addition, this list includes trees given the Award of Garden Merit (AGM) by the Royal Horticultural Society (Armitage et al., 2009) which would be of interest to the public as examples of trees for urban gardens.

As there are over four Betula pendula, five Betula pubescens, two Betula pubescens $\times$ pendula and 12 Betula indet. some of these trees could be replaced with taxa which are missing.

A molecular study of Betula at Glasnevin would be desirable. This would help to verify existing identifications. Such a study would also aid the identification of those trees which were unidentifiable in this project and would help to determine the parents of suspected hybrids.

As far as new plant material is concerned only cultivars should be obtained from nurseries. Betula species should be sourced from wild-collected seed of known provenance. All of these seeds should be grown on until one good specimen is obtained for planting out and the rest dispersed to Mount Usher, Kilmacurragh, and John F. Kennedy Arboretum, Wexford in order to increase wild collections with known provenance of Betula in Ireland. Cuttings can be taken where seed is not available.

\section{ACKNOWLEDGEMENTS}

I would like to thank Dr Paul Fitters, Tutor and Supervisor, Teagasc Horticultural College, Dr Matthew Jebb, Director, and Alexandra Caccamo and Colette Edwards, Librarians, at the National Botanic Gardens of Ireland, and Dr Sven Landrein, Botanist, Royal Botanic Gardens, Kew. 


\section{BIBLIOGRAPHY AND REFERENCES}

ARMITAGE, J., CURLY, J., EDWARDS, D. \& LANCASTER, N. (eds) (2009). RHS Plant Finder 2009-2010, 23rd edition. London: Dorling Kindersley Ltd.

ASHBURNER, K.B. (1992). Birch species and their barks. Proceedings of Betula Symposium. Kington: International Dendrology Society.

BRIDSON, D. \& FORMAN, L. (1992). The Herbarium Handbook. London: Kew Publishing.

CHEN, Z.D., MANCHESTER, S.R. \& SUN, H.Y. (1999). Phylogeny and evolution of the Betulaceae as inferred from DNA sequences, morphology and paleobotany. American Journal of Botany, 86(1), 1,168-1,181.

CLARKE, D.L. (ed.) (1996). W.J. Bean Trees and Shrubs Hardy in the British Isles, London: M. Bean and John Murray Publishers.

DE JONG, P.C. (1992). An introduction to Betula: its morphology, evolution, classification and distribution, with a survey of recent work. Proceedings of Betula Symposium. Kington: International Dendrology Society.

GOVAERTS, R. \& FRODIN, D.G. (1998). World Checklist and Bibliography of Fagales. London: Kew Publishing.

HUXLEY, A. (ed.) (1992). The New Royal Horticultural Society Dictionary of Gardening. London: Macmillan Press Ltd.

SARGENT, C.S. (1905). Manual of the Trees of North America. Cambridge, MA: Harvard University Press.

SPJUT, R.W. (1994). A Systematic Treatment of Fruit Types. Memoirs of New York Botanical Garden Vol. 70. Available at: www.worldbotanical.com/fruit_types.htm (accessed July 2011).

SPONGBERG, S.A. (1990). Journal of the Arnold Arboretum. Cambridge, MA: Harvard University Press. 


\section{APPENDIX 1}

Example of a pro-forma sheet completed as part of the identification process.

B. albosinensis var. septentrionalis (Burkill) 1899 Chinese red birch

Accession: XX.013763

Position: A4 MapPos 15

Provenance: Unknown

Reference used:

'New RHS Dictionary of Gardening'

'The Plantsman 1-2, 1979-1981'

Compared to B. albosinensis var. septentrionalis description:

Reference Yes No Specimen

Size $\quad 18-25 m$

Bark Peeling

Thin

Orange/red

Dull

White lenticels

Young bark glaucous

Twigs Young glandular/pubescent Mature glabrous/dark brown Shiny

Leaf $\quad 12 \times 7 \mathrm{~cm}$

Narrowly ovate to lanceolate Apex long acuminate

Base rounded

Sharply double serrate Young hairy between veins Veins beneath silky haired Tufts of hairs in axils Veins 10-14 pairs Petiole $6-12 \mathrm{~mm}$

Catkins Male 6 x $0.5 \mathrm{~cm}$ Female oval or cylindric

Samaras Elliptic

Bract Rounded lateral lobes

pecimen

\section{$\checkmark$}

$\checkmark$

2

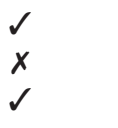

older twigs
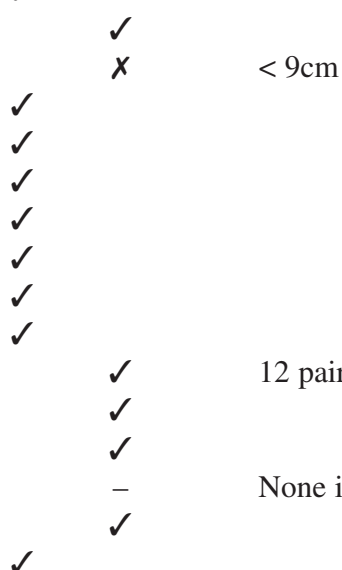

$<9 \mathrm{~cm}$

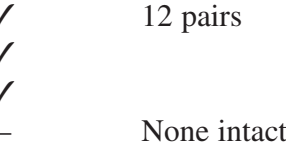

Comparison with herbarium specimen:

No herbarium specimen.

\section{Conclusion:}

This was compared to B. albosinensis var. septentrionalis which has been changed to $B$. utilis. But this specimen fits with B. albosinensis and not B. utilis.

Re-identified as $\boldsymbol{B}$. albosinensis 